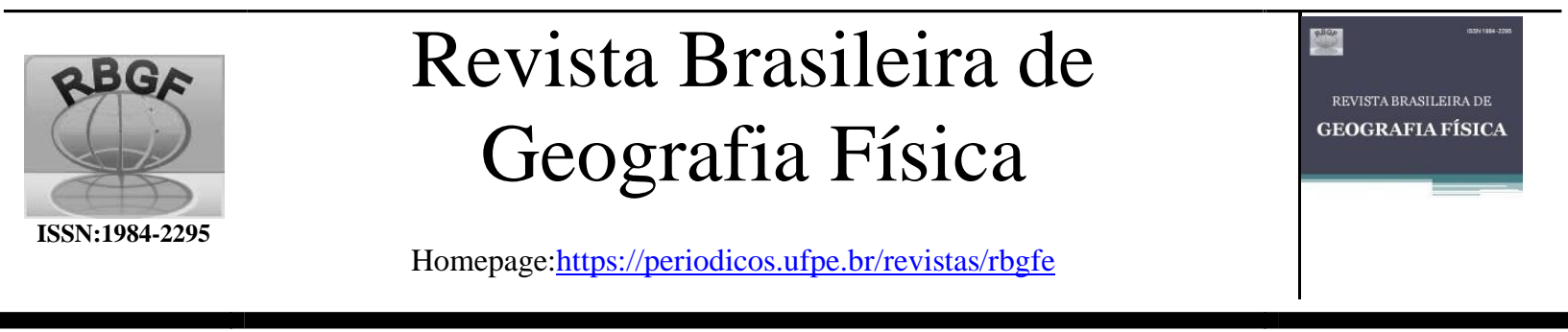

\title{
Utilização da Lógica Fuzzy como suporte ao Zoneamento Ambiental: um estudo de caso em Paracatu - MG
}

\begin{abstract}
Arthur Pereira dos $\operatorname{Santos}^{1}$, Fernando Luiz de Paula Santil ${ }^{2}$, Petronio Silva de Oliveira ${ }^{3}$, José Arnaldo Frutuoso Roveda ${ }^{4}$ ${ }^{1}$ Doutorando em Ciências Ambientais pela Universidade Estadual Paulista "Júlio de Mesquita Filho", Alto da Boa Vista, Sorocaba, 18087180, São Paulo. (15) 3238-3400 arthur.p.santos@ unesp.br (autor correspondente). ${ }^{2}$ Dr. em Ciências Geodésicas pela Universidade Federal do Paraná, Professor Dr. Adjunto da Universidade Federal de Uberlândia, no Curso de Engenharia de Agrimensura e Cartográfica, Monte Carmelo, Minas Gerais. Rodovia LMG 746, km 01 - Trevo, 38500000 - Monte Carmelo, Minas Gerais, (34) 3810-1036. fernando.santil@ ufu.br. ${ }^{3}$ Doutorando em Ciências Ambientais pela Universidade Estadual Paulista "Júlio de Mesquita Filho", Alto da Boa Vista, Sorocaba, 18087180, São Paulo. (15) 3238-3400, petronio.silva@ unesp.br. ${ }^{4}$ Dr. em Matemática pela Universidade de Brasília, Professor Dr. da Universidade Estadual Paulista "Júlio de Mesquisa Filho" - UNESP, Alto da Boa Vista, Sorocaba, 18087180, São Paulo. (15) 3238-3400, São Paulo. jose.roveda@ unesp.br ${ }^{4}$

Artigo recebido em 22/03/2021 e aceito em 13/07/2021
\end{abstract}

\section{RE S UMO}

Fazer uso das geotecnologias para mapear os níveis de fragilidade ambiental de um município é uma importante estratégia de planejamento ambiental a ser utilizada em processos de Zoneamento Ambiental (ZA), principalmente no que tange ao uso consciente dos recursos naturais da área. Portanto, o objetivo desta pesquisa foi realizar, por meio da implementação de geotecnologias, um estudo de fragilidade ambiental em um município ocupado, intensivamente, por atividades minerárias e pela agropecuária, para que seja utilizado como subsídio aos gestores municipais em seu ZA. Como estudo de caso, adotou-se o município de Paracatu - Minas Gerais. Levantou-se aspectos pedológicos, litológicos, hidrográficos, hipsométricos, de declividade e de uso e ocupação da terra, além da rede de drenagem, do limite municipal e da atividade de mineração. Por fim e por meio de Lógica Fuzzy com o uso de pesos definidos pelo método Analytical Hierarchical Process (AHP), utilizou-se os mapas de declividade, uso e cobertura da terra, litologia, pedologia e rede de drenagem para elaboração de um mapa de fragilidade ambiental do município. Concluiu-se que o município possui características de susceptibilidade a impactos ambientais negativos, principalmente em sua malha urbana e na área de extração mineral a céu aberto, e que esses podem ser melhor avaliados a partir da utilização de geotecnologias direcionadas para o subsídio do planejamento urbano, sendo esse, de extrema importância para o município de Paracatu - MG, que atualmente está passando por mudanças em seu plano diretor e possui intenções de crescimento urbano.

Palavras-chave: Geotecnologias. Zoneamento Ambiental. Planejamento ambiental.

\section{Use of Fuzzy Logic to support Environmental Zoning: a case study in Paracatu - MG}

\section{A B S T R A C T}

The use of geotechnologies to map the levels of environmental fragility in a municipality is an important environmental planning strategy, especially when it is intended to make a conscious use of the area's natural resources through its zoning. Therefore, the objective of this research was to carry out, through the implementation of geotechnologies, a study of environmental fragility in a municipality occupied, intensively, by mining activities and agriculture. As a case study, the municipality of Paracatu - Minas Gerais was adopted. Pedological, lithological, hydrographic, hypsometric, declivity and land use and occupation aspects were raised, in addition to the drainage network, the municipal boundary and mining activity. Finally, using Fuzzy Logic with the use of weights defined by the Analytical Hierarchical Process (AHP) method, the maps of slope, land use and cover, lithology, pedology and drainage network were used to prepare a map of environmental fragility of the municipality. It was concluded that the municipality is susceptible to negative environmental impacts, mainly in its urban network and in the area of open-pit minning, and that these can be better evaluated through the use of geotechnologies aimming at subsidizing urban planning, which is extremely important for the municipality of Paracatu - MG, which is currently undergoing changes in its master plan and intends to expand. Keywords: Geotechnology. Environmental Zoning. Environmental Planning.

\section{Introdução}

O planejamento ambiental, processo contínuo e que envolve a coleta, a organização e a análise sistematizada de informações do meio físico a partir de procedimentos e métodos específicos possui, dentre as suas características e finalidades, a de 


\section{Revista Brasileira de Geografia Física v.014, n.04 (2021) 2352}

proporcionar apoio aos gestores públicos em suas tomadas de decisões voltadas para atingir melhorias no aproveitamento dos recursos naturais que, quando realizado de forma adequada, promove vantagens para a população e minimiza os impactos negativos no meio socioambiental (Baldwin, 2019).

Nesse contexto, as geotecnologias têm se apresentado como uma área científica importante que atende aos estudos de planejamento envolvendo as dimensões territoriais. Trata-se de um conjunto de técnicas e métodos científicos aplicados à análise e à exploração de recursos naturais, em diferentes escalas geográficas, que auxiliam desde estudos da paisagem, passando por variáveis ambientais, até a análise e a prevenção de desastres (Embrapa, 2014).

Atrelado a esse contexto, encontra-se o ZA, instrumento técnico aplicado por planejadores no controle do desenvolvimento das cidades de forma que seja realizada a divisão, norteada a partir das características ambientais, sociais e/ou econômicas da área em questão, em determinadas porções ou zonas menores, de forma que determinada atividade seja autorizada ou restritas a operarem no local (Silva et al., 2021). Nesse sentido, o Instituto Brasileiro de Geografia e Estatística (IBGE) divulgou, em seu último censo, que $84 \%$ da população brasileira residia em áreas urbanas (IBGE, 2010). Além disso, nas últimas décadas, o Brasil passou por um processo de intensa urbanização desenfreada. Dessa forma, e com esse processo não ocorrendo de forma planejada, a população inicia o seu processo de ocupação em áreas que não possuem a mínima estrutura para recebê-los, ocasionando em problemas ambientais, sociais e associados à segurança da população, havendo a necessidade de estudos que possam frear ou remediar tais obstáculos.

O ZA foi caracterizado, inicialmente, por ser um instrumento de auxílio no planejamento e no ordenamento territorial, tanto em escala regional como em escala local, pois os estudos que o abordam possibilitam a caracterização das áreas quanto às suas aptidões e restrições as atividades já em desenvolvimento ou a serem implantadas. Ademais, possui a capacidade de indicar porções de um determinado terreno com uma maior qualidade ambiental.

Nesse contexto, a utilização das geotecnologias como subsídio ao planejamento e ao ZA permite, dentre outros fatores, definir os setores de um território que apresentam peculiaridades ambientais. Dessa forma, é possível propor o uso adequado, a preservação ou mesmo a recuperação ou reabilitação das áreas que se encontram degradadas por atividades que sejam incompatíveis com seu uso.

Atualmente, diante do fácil acesso aos dados espacializados, é possível realizar a sua integração em
Sistemas de Informação Geográfica (SIG) por meio da aplicação de técnicas de inferência espacial. Os modelos de inferência mais utilizados, atualmente, são: Lógica Fuzzy, operadores booleanos e sobreposição por índice, porém, com relação a estudos envolvendo dinâmicas ambientais, os baseados na Lógica Fuzzy obtiveram os melhores resultados, conforme estudos correlatos (Krishnan et al., 2020; Collins e Kumral, 2020; Hannan et al., 2021).

Fazer uso das geotecnologias para se mapear os níveis de fragilidade ambiental que um município, intensamente exposto às atividades antrópicas, é uma importante estratégia de planejamento ambiental, principalmente quando se pretende fazer o uso consciente dos recursos naturais da área. Todavia, até o presente momento, não se tem esse tipo de informação para o município de Paracatu - Minas Gerais (MG), área de estudo do presente trabalho, mesmo em se tratando de uma importante região econômica para o estado de Minas Gerais.

A escolha dessa área se deu pelo fato de que, de acordo com o Atlas do Desenvolvimento Humano no Brasil (ADHB), entre 2000 e 2010, a população de Paracatu cresceu a uma taxa média anual de 1,20\%, enquanto, no Brasil, essa taxa foi de $1,17 \%$ para o mesmo período. Já na década de 90 , a população do município cresceu a uma taxa média anual de 2,03\%, enquanto, no Brasil, essa taxa foi de $1,63 \%$ para o mesmo período. Ressalta-se que, para esse período, a taxa de urbanização municipal passou de $79,19 \%$ para $83,78 \%$ (Atlas do desenvolvimento humano no brasil, 2021).

Com a finalidade de preencher essa lacuna, esse trabalho tem por objetivo construir um diagnóstico ambiental do município de Paracatu. Para isso, são mapeados os aspectos pedológicos, litológicos, hidrográficos, hipsométricos, de declividade e de uso e ocupação da terra do município, bem como identificado o limite territorial da atividade de mineração e da rede de drenagem municipal. Na sequência, esses dados são utilizados para a identificação dos níveis de fragilidade ambiental do município por meio de inferência geográfica. Portanto, aplicou-se a lógica Fuzzy para a padronização das variáveis e o método AHP para a ponderação delas, conforme abordagem de estudos correlatos (Gonçalves et al., 2016; Messias e Ferreira, 2017; Machado et al., 2018; Pereira et al., 2019; Carvalho et al., 2020).

Convém ressaltar que a identificação dos ambientes naturais e as suas respectivas fragilidades podem proporcionar uma melhor definição de estratégias e diretrizes a serem implementadas no espaço físico-territorial. Porém, para tal identificação, é necessário que modelos simulem a integração dos 
Revista Brasileira de Geografia Física v.014, n.04 (2021) 2352

processos naturais e antrópicos. Portanto, a principal contribuição desse trabalho é a possibilidade de disponibilizar informações que caracterizem o município de Paracatu em sua totalidade, principalmente no que tange as suas fragilidades ambientais.

\section{Procedimentos metodológicos}

\section{Área de Estudo}

O município de Paracatu (Figura 1) está localizado na mesorregião noroeste do estado de Minas Gerais, distando 220 km de Brasília e a 500 km de Belo Horizonte. Paracatu conta com uma população atual de aproximadamente 93 mil habitantes (IBGE, 2021).

A economia do município está voltada para a exploração mineral e para a agropecuária. A agricultura moderna e a pecuária intensiva são caracterizadas como exploração agrícola rudimentar de subsistência e pecuária extensiva. Paracatu, ainda, apresenta destaque na atividade turística, por ser uma cidade histórica, e do ecoturismo, devido à presença de grutas, cachoeiras, montanhas e trilhas (Souza et al., 2010).

A KINROSS Gold Corporation atua nas atividades de pesquisa e desenvolvimento mineral, mineração, beneficiamento e comercialização de ouro $(\mathrm{Au})$, sendo uma das maiores produtoras de $\mathrm{Au}$ do Brasil, responsável por $22 \%$ da produção nacional. Em 2006, essa empresa iniciou um projeto de expansão que elevou a capacidade de lavra de minério para 61 Mtpa e fez com que a produção anual de $\mathrm{Au}$ em Paracatu praticamente triplicasse, chegando a 17 toneladas por ano. O projeto também ampliou em mais de 15 anos o tempo de vida útil da mina, agora estimado até 2030 (Kinross Gold Corporation, 2021). Atualmente, devido à expansão, a mina está localizada a poucos metros da zona urbana de Paracatu.

O desenvolvimento tecnológico da indústria mineral é o que possibilita a exploração de Au em tipo de depósito aurífero no município, ou seja, o Au contido em rocha dura (Kinross Gold Corporation, 2021). Essa atividade foi realizada, inicialmente, pela empresa Rio Paracatu Mineração (RPM), onde, estudos realizados na década de 1980 levaram à cubagem de uma jazida de baixo teor aurífero no local denominado Morro do Ouro, justamente no limite da zona urbana da cidade.

Além do $\mathrm{Au}$, a mineração no município ocorre, também, com a exploração de Zinco (Zn) e Chumbo $(\mathrm{Pb})$, sendo esses de responsabilidade da multinacional NEXA Resources, antiga Votorantim Metais Zinco, com início das operações datadas em 1988 (Nexa, 2021). De acordo com informações coletadas no sítio eletrônico da empresa, em 2010, recebeu o prêmio de maior produtora de $\mathrm{Zn}$ da América Latina e, já no ano de 2012, tornou-se a maior fabricante de níquel eletrolítico da América Latina, líder no mercado brasileiro de alumínimo e posicionada entre as cinco maiores produtoras de $\mathrm{Zn}$ do mundo (Nexa, 2021).

Em Paracatu, a Nexa atua na atividade de mineração na mina Morro Agudo, situada $50 \mathrm{~km}$ da malha urbana do município. Além do $\mathrm{Zn}$, ocorre no local a extração de pó de calcário, sendo esse um subprotudo comercializado como corretivo na agricultura (Nexa, 2021). 
Revista Brasileira de Geografia Física v.014, n.04 (2021) 2352

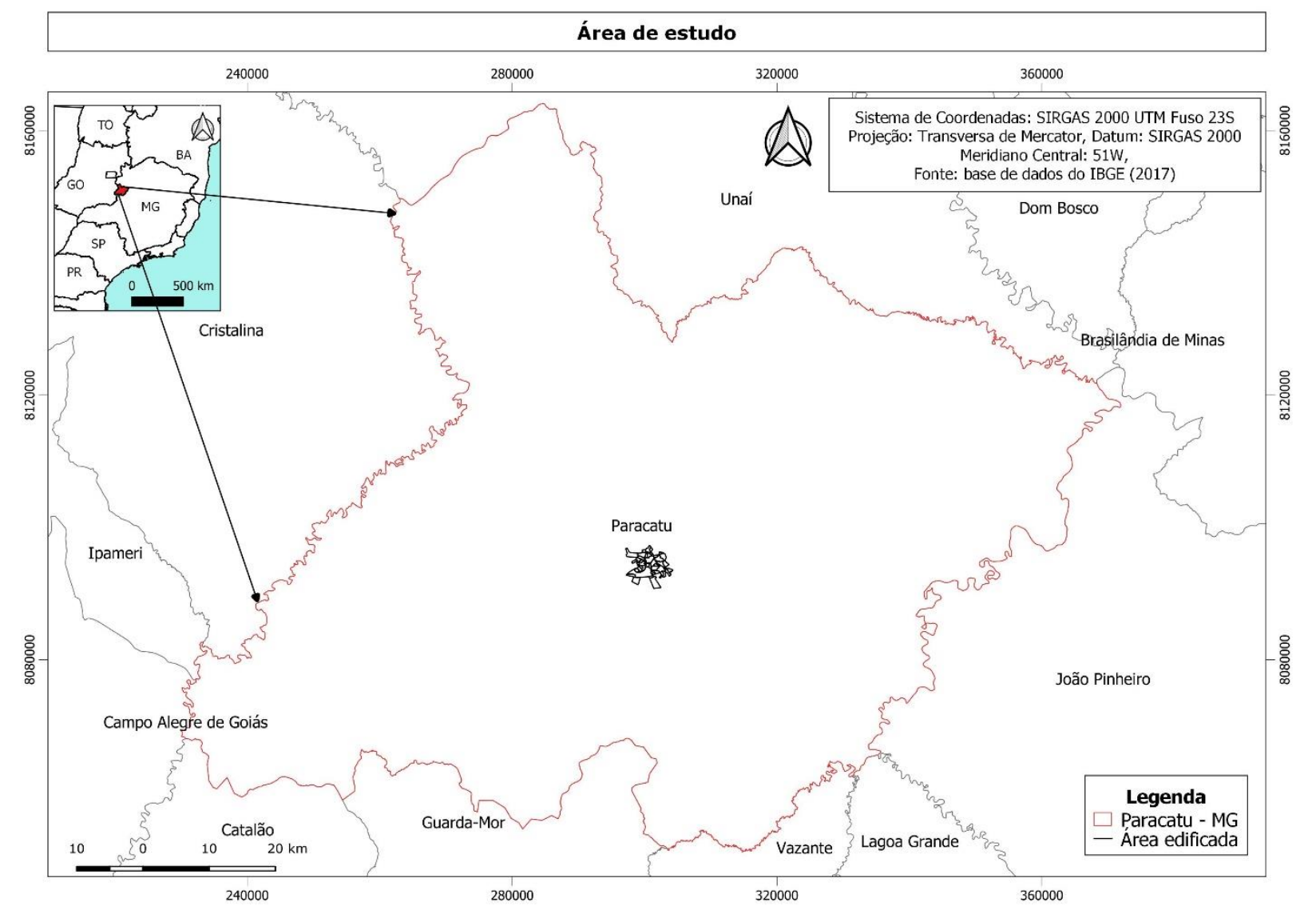

Figura 1. Localização geográfica do município de Paracatu - MG.

A mineração e os conflitos sociais e ambientais em Paracatu $-M G$

$\mathrm{O}$ contexto socioambiental relacionado à atividade de mineração no município engloba conflitos de interesse de todas as partes. Por ser responsável por grande parte do Produto Interno Bruto (PIB) do local e gerar, aproximadamente, 5000 empregos diretos e indiretos, o fator "dependência", em determinadas ocasiões, compete com os fatores sociais e ambientais (Castilhos et al., 2020).

Diariamente, no período da tarde (entre $15 \mathrm{~h}$ e $16 \mathrm{~h}$ ), centenas de buracos são detonados com explosivos. Vale ressaltar que, no Brasil, o minério de onde é extraído o Au é rico em arsenopirita, ou seja, o Au encontra-se associado ao arsênio (As). Isso acontece, por exemplo, em Ouro Preto - MG, onde as águas subterrâneas presentes em antigas minas de ouro registram presença de doses significativas desse elemento tóxico, e também em outros locais como Crixás - GO e na Fazenda Brasileiro - BA (Araújo et al., 2014).

Nesse sentido, o Instituto Mineiro de Gestão das Águas (IGAM) editou a Portaria n n $^{\circ}$, de 07 de fevereiro de 2020, definindo a Suspensão Temporária das outorgas de direito de uso de recursos hídricos no Córrego Rico e na sua bacia de contribuição por 5 anos, a contar da publicação. A portaria, já em vigor, foi publicada no Diário do Executivo no dia 18 de fevereiro (IGAM, 2020).

$\mathrm{O}$ exposto se deve à Nota Técnica $\mathrm{n}^{\circ}$ 30/IGAM/GEMOQ/2019, que verificou, no Córrego Rico, valores elevados de As, sobretudo no trecho localizado a jusante do município de Paracatu, cujos valores chegam a ultrapassar os limites legais em 100 vezes (IGAM, 2020).

A nota técnica supracitada destaca que o As apresenta elevada toxidez para a biota e para a população humana, ademais, informa que o trecho do córrego Rico avaliado não está apto para os usos estabelecidos para águas de Classe 2, quais sejam, abastecimento para consumo humano após tratamento convencional; recreação de contato primário; irrigação; aquicultura e atividade de pesca (IGAM, 2020).

Em relação aos conflitos sociais, além da proximidade da área de exploração mineral com a malha urbana do município, o Ministério Público Federal (MPF) pressupôs que a expansão da mineradora causou e, ainda causa, danos patrimoniais e morais às famílias quilombolas Machadinho, 


\section{Revista Brasileira de Geografia Física v.014, n.04 (2021) 2352}

Amaros e São Domingos que habitavam e/ou habitam a região (MPF, 2010).

Esse contexto é relacionado ao fato de que, em suas expansões, a mineradora comprava as áreas dos quilombolas e, consequentemente, desagregava do local as suas identidades culturais (Souza et al., 2010; MPF, 2010).

Além disso, com o projeto de expansão, houve a necessidade de construir uma nova barragem de rejeitos, ocupando um vale que, originalmente, pertencia à comunidade quilombola Machadinho (Souza et al., 2010).

Diante desse conflito, a Justiça Federal, localizada em Patos de Minas - MG, concedeu uma liminar na Ação Civil Pública que proibia a mineradora de realizar qualquer atividade, em um raio de 500 metros, da comunidade remanescente Quilombo dos Amaros (MPF, 2010).

\section{Produção Cartográfica}

Para atingir o objetivo proposto, foram elaborados os seguintes mapas temáticos: mapa pedológico, litológico, hidrográfico, hipsométrico, mapa de declividade, de uso e ocupação da terra, e mapa da rede de drenagem municipal.

Para a elaboração do mapa pedológico e do mapa hidrográfico, compilou-se dados em formato vetorial, na geometria de polígono, referentes à pedologia e hidrografia do município, disponibilizados no banco de dados geográficos do IBGE. O processo de compilação consistiu no download desses dados, na escala de 30 metros, sistema SIRGAS 2000, recorte para o limite do município em estudo e projeção dos dados no sistema Universal Transverso de Mercator (UTM), fuso 23 Sul. As cores definidas para cada classe de pedologia e da hidrografia foram sugeridas nos manuais técnicos do IBGE (1999; 2007 e 2009).

Os dados referentes à declividade e à hipsometria foram extraídos a partir de imagens de radar coletadas na missão Shuffle Radar Topographic Mission (SRTM), disponibilizada pela United States Geological Service (USGS) com resolução espacial equivalente a 30 metros. Para recobrir a área do município, foram necessárias quatro imagens SRTM, que foram mosaicadas com auxílio do software opensource QGIS 2.18. Para o mapa de declividade do município, as classes foram definidas de acordo com o Manual de Obtenção de Terras do Instituto Nacional de Colonização e Reforma Agrária (INCRA), sendo: plano (0-2\%); suave ondulado (2$5 \%$ ); ondulado (5-15\%) e forte ondulado (15-45\%) (INCRA, 2006). Quanto a geração do mapa hipsométrico, as seguintes classes de elevações foram definidas: baixa $(<494$ m) média-baixa (494 e <
$625 \mathrm{~m})$; média (625 e < $756 \mathrm{~m})$; média- alta (756 m e $<888 \mathrm{~m})$ e alta $(888-1020 \mathrm{~m})$. Essa definição foi baseada na separação em intervalos iguais dos valores obtidos para a área do município.

Para a elaboração do mapa de uso e cobertura da terra, utilizou-se uma imagem Landsat 8, sensor Operational Land Imager (OLI), registrada em 2 de agosto de 2017, com nula presença de nuvens. A imagem foi adquirida a partir da plataforma Science Research and Development (LSRD), disponibilizada pela USGS, cujo dado encontra-se no nível HighLevel Data, ou seja, sem a necessidade de passar por etapas de pré-processamento, como as correções radiométrica, geométrica e atmosférica. Em seguida, combinou-se as bandas espectrais 6, 5 e 4 (RGB) para o processo de interpretação visual e de extração de amostras. A partir da análise visual, as seguintes classes temáticas foram identificadas: cultura agrícola; corpo d'água; área da mineradora; solo exposto; área urbana; vegetação arbórea e; pastagem. Feito isso, a imagem foi classificada com o algoritmo de distância mínima usando o software open-source do QGIS 2.18.

Para avaliar a performance da classificação do algoritmo utilizado, realizou-se a validação dos resultados a partir do cruzamento dos pixels classificados com as áreas definidas como referência terrestre. Foram coletados 20 pontos por classe e os pontos foram levantados e verificados com auxílio de imagens de alta resolução, observadas no GoogleEarth Pro e validadas com conhecimento prévio do município. A partir de então, calculou-se a acurácia global e o índice Kappa. A classificação por distância mínima apresentou acurácia global de 83,58 e índice Kappa equivalente a 0,75.

\section{Padronização das Variáveis por Função Fuzzy}

Para a padronização do conjunto de dados de pedologia, litologia, uso e cobertura e declividade, primeiramente, realizou-se a transformação desses dados no formado vetorial para o formato matricial, processo esse denominado de rasterização e apresentado por García (2019).

Em seguida, transformou-se os mapas temáticos qualitativos em mapas temáticos quantitativos. A transformação de um campo nominal para um campo numérico é denominada ponderação, e essa transformação é, normalmente, aplicada quando há a exigência de se determinar ou associar um valor, indicando um peso a cada uma das classes representadas, conforme apresentado por Peixoto et al. (2019).

Nesse sentido, o valor 0 (zero) corresponde a uma hipótese testada não satisfeita, enquanto o valor 1 (um) corresponde a essa hipótese satisfeita. No presente estudo, a padronização foi realizada por funções de 
Revista Brasileira de Geografia Física v.014, n.04 (2021) 2352

pertinência Fuzzy, em que a aproximação do valor 1 condiz com a hipótese de maior fragilidade ambiental da área e valor 0 representa um meio totalmente estável. Para os dados de pedologia, litologia e uso e cobertura da terra, atribuíram-se os valores apresentados na Tabela 1 .

Tabela 1. Pesos atribuídos às feições pedológicas, hidrogeológicas e de uso e cobertura da área.

\begin{tabular}{|c|c|c|c|c|c|}
\hline \multicolumn{2}{|c|}{ Pedologia } & \multicolumn{2}{|c|}{$\begin{array}{c}\text { Uso e cobertura da } \\
\text { Terra }\end{array}$} & \multicolumn{2}{|c|}{ Litologia } \\
\hline $\begin{array}{c}\text { Classe } \\
\text { Temática }\end{array}$ & Peso & $\begin{array}{l}\text { Classe } \\
\text { Temática }\end{array}$ & Peso & $\begin{array}{c}\text { Classe } \\
\text { Temática }\end{array}$ & Peso \\
\hline Cambissolo & 0,6 & Mineradora & 0,8 & $\begin{array}{c}\text { Ardósia/ } \\
\text { Quartzito/ } \\
\text { Foforito/ } \\
\text { Dolomito/ } \\
\text { Siltito } \\
\end{array}$ & 0,5 \\
\hline Plintossolo & 0,8 & Vegetação & 0,6 & $\begin{array}{c}\text { Areia/Argila } \\
/ \\
\text { Cascalho }\end{array}$ & 0,5 \\
\hline Gleissolo & 0,8 & Cultura & 0,6 & $\begin{array}{l}\text { Arenito/ } \\
\text { Argilito/ } \\
\text { Laterita }\end{array}$ & 0,5 \\
\hline Latossolo & 0,5 & $\begin{array}{l}\text { Corpo } \\
\text { Hídrico }\end{array}$ & 0,9 & Filito & 0,5 \\
\hline \multirow[t]{2}{*}{ Neossolo } & 0,5 & $\begin{array}{c}\text { Solo } \\
\text { Exposto }\end{array}$ & 0,9 & $\begin{array}{c}\text { Filito/ } \\
\text { Quartzito/ } \\
\text { Metassiltito }\end{array}$ & 0,5 \\
\hline & & Pastagem & 0,8 & $\begin{array}{c}\text { Metarenito/ } \\
\text { Quartzito/ } \\
\text { Metassiltito/ } \\
\text { Filito }\end{array}$ & 0,5 \\
\hline
\end{tabular}

Pedologia: No mapa pedológico, com relação as classes temáticas, pesos idênticos foram atribuídos as classes de Gleissolo e de Plintossolo. Ambos os solos receberam maiores pesos em relação as demais classes pelo fato de se tratar de solos considerados de mal a muito mal drenados, havendo nesses solos restrição à percolação da água; considerados como mais frágeis (EMBRAPA, 1997).

Com relação aos Latossolos, esses receberam peso intermediário por se tratar de solos que possuem, segundo a Empresa Brasileira de Pesquisa Agropecuária, Embrapa, boas condições físicas para o uso agrícola, associadas a uma boa permeabilidade, e por serem solos bem estruturados e muito porosos.

Em relação ao Neossolo e ao Cambissolo, esses receberam pesos intermediários por se tratarem de solos variáveis e serem constituídos pela heterogeneidade do material de origem, das formas de relevo e das condições climáticas, ou seja, pode existir solos rasos até profundos e de baixa ou alta permeabilidade (EMBRAPA, 1997).

Uso e cobertura: Em relação as classes de uso e cobertura, as classes referentes ao Solo Exposto e Corpo Hídrico receberam peso maior por se tratar de áreas vulneráveis e que dependem de um manejo adequado para a sua manutenção. As classes relacionadas com as atividades antrópicas (Mineração e Cultura) receberam o mesmo peso entre si e, com relação as classes de Cultura e Vegetação, pressupõe-se que esses locais ou passaram por correções de manejo adequada ou encontram-se com suas características naturais preservadas, recebendo, portanto, o mesmo peso.

Litologia: Devido a heterogeneidade das classes litológicas acopladas em uma determinada classe, todas as classes receberam peso intermediário.

Rede de drenagem: Com relação a padronização do conjunto de dados da rede de drenagem, inicialmente, deve-se destacar que o dado se encontrava em forma vetorial, na geometria de linha. No software da ESRI ArcGIS 10.5, criou-se um raster a partir do cálculo da distância euclidiana entre as linhas (cujo limite era o limite municipal). Atribuiu-se o valor de $30 \mathrm{~m}$ para o tamanho da célula (pixel) para corresponder à resolução espacial adotada nos demais produtos temáticos. Os valores encontrados variaram de $0 \mathrm{a}$ $8,325 \mathrm{~m}$. Para padronizar esse raster entre os intervalos de 0 e 1 , uma função linear decrescente foi atribuída considerando os valores de mínimo $(0 \mathrm{~m}) \mathrm{e}$ máximo $(8.325 \mathrm{~m})$, uma vez que se considerou que quanto mais próximo do canal d'água, maior a fragilidade (portanto, valor mais próximo de 1).

Declividade: Para padronizar os valores em percentagem do raster de declividade, aplicou-se uma função linear crescente e considerando os valores de mínimo (0\%) e de máximo (45\%) como respectivos 0 e 1. Essa função foi aplicada justamente por entender que quanto maior a declividade local, maior a fragilidade de determinado ambiente.

\section{Ponderação das Variáveis pelo Método AHP e Álgebra de Mapas}

A partir da padronização dos dados no intervalo 0 a 1 , a próxima etapa do método empregado consistiu-se na determinação da importância relativa de cada mapa temático elaborado. Para esse caso, adotou-se o método de comparação pareada AHP, proposto por Saaty (1990).

Esse método tem por finalidade organizar e avaliar diferentes níveis de importância entre critérios distintos, medindo a consistência dos julgamentos, conforme estudos correlatos (Santos e Rocha, 2019; Caggy e Almeida, 2020; Oliveira et al., 2020). Convém destacar que o modelo requer uma estruturação hierárquica e deve comparar os critérios de acordo com a importância relativa, as preferências 
Revista Brasileira de Geografia Física v.014, n.04 (2021) 2352

e a probabilidade entre dois critérios. Para tanto, utiliza-se uma escala de valores (Tabela 2).

Tabela 2. Escala de valores para a comparação pareada pelo método AHP.

\begin{tabular}{c|c|c}
\hline Intensidade & Importância & Explicação \\
\hline 1 & Igual & $\begin{array}{c}\text { Ambos os fatores } \\
\text { contribuem igualmente }\end{array}$ \\
\hline 3 & Moderada & $\begin{array}{c}\text { Um fator é um pouco } \\
\text { mais importante que o } \\
\text { outro }\end{array}$ \\
\hline 5 & Essencial & $\begin{array}{c}\text { Um fator é claramente } \\
\text { mais importante que o } \\
\text { outro }\end{array}$ \\
\hline 9 & Extrema & $\begin{array}{c}\text { Um fator é fortemente } \\
\text { favorecido e sua } \\
\text { relevância foi } \\
\text { demonstrada }\end{array}$ \\
\hline $2,4,6,8$ & Intermediário & $\begin{array}{c}\text { Aaferencia que } \\
\text { diferencia os fatores é } \\
\text { da maior ordem } \\
\text { possível }\end{array}$ \\
\hline
\end{tabular}

$\mathrm{O}$ valor dos pesos obtidos pelo método AHP indica a importância relativa dos critérios analisados e permite regular a compensação entre eles, conforme apresentado na Tabela 3. Com relação à Razão de Consistência (CR), essa foi de 0,072 , sendo esse, um valor aceitável, uma vez que é menor que 0,1 (Câmara e Monteiro, 2004).

A etapa subsequente consistiu na construção do mapa de fragilidade pelo processo de inferência geográfica. Para isso, adotou-se a técnica de combinação linear ponderada entre as variáveis padronizadas (mapas), no intervalo entre 0 e 1 , sendo seus respectivos pesos gerados pelo método AHP (Tabela 3).

As classes temáticas quantitativas foram definidas para a legenda do mapa de fragilidade ambiental, sendo os valores de tais classes correspondentes a: Muito Baixo $(<0,49)$, Baixo $(0,5$ a 0,53); Médio (0,54 a 0,57); Alto (0,57 a 0,6); Muito Alto $(>0,6)$. O intervalo de valores dessas classes foi definido segundo o método de quebras naturais (Jenks).

Tabela 3. Comparação pareada entre os fatores e cálculo dos pesos.

\begin{tabular}{|c|c|c|c|c|c|}
\hline Fatores & $\begin{array}{l}\text { Rede de } \\
\text { drenagem }\end{array}$ & Declive & $\begin{array}{l}\text { Pedo- } \\
\text { logia }\end{array}$ & $\begin{array}{l}\text { Litolo- } \\
\text { gia }\end{array}$ & $\begin{array}{c}\text { Uso e } \\
\text { cobertura }\end{array}$ \\
\hline $\begin{array}{c}\text { Rede de } \\
\text { drenagem }\end{array}$ & 1 & & & & \\
\hline $\begin{array}{c}\text { Declivida } \\
\text { de }\end{array}$ & 5 & 1 & & & \\
\hline Pedologia & 5 & 3 & 1 & & \\
\hline Litologia & 5 & 2 & 5 & 1 & \\
\hline $\begin{array}{c}\text { Uso e } \\
\text { cobertura }\end{array}$ & 5 & 5 & 5 & 5 & 1 \\
\hline Peso & 0,145 & 0,181 & 0,104 & 0,161 & 0,410 \\
\hline
\end{tabular}

\section{Resultados e discussão}

Por meio dos resultados do mapa de declividade (Figura 2), constata-se que o município de Paracatu é dividido, em sua maioria, em áreas planas e de declive ondulado. Essas condições influenciam diretamente no desempenho de escoamento superficial da região, considerando que a área urbana do município se encontra em encostas de declive ondulado (5-15\%) e forte ondulado (15$45 \%)$.

Estudo realizado por Rezende e Marques (2017) verificou que, com relação aos riscos de inundação na área urbana do município de Paracatu, o percentual é mais alto nas áreas impermeáveis devido à presença de solos jovens associados à ocupação urbana. Ainda de acordo com os autores, ocorre a contribuição para o aumento da velocidade e do volume de escoamento superficial das águas urbanas, aumentando, com frequência, o número de inundações e poluição difusa pela lavagem das superfícies urbanizadas. Por fim, verificou-se que, na cidade de Paracatu, 36\% da parte urbanizada é considerada por possuir alto risco de inundação, seguida pelas classes de médio risco $(26 \%)$ e muito alto risco $(25 \%)$.

Com relação ao declive ondulado, de acordo com a cartilha de solos e avaliação do potencial agrossilvipastoril das microrregiões Paracatu e Unaí, disponibilizada pela Empresa de Pesquisa Agropecuária de Minas Gerais (EPAMIG) e elaborada por Naime et al. (2014), esse nível de declive pode variar para mais quando as condições físicas forem muito favoráveis, ou para menos de $8 \%$ quando muito desfavoráveis, como é o caso de solos com horizonte A arenoso, e mudança textural abrupta para o horizonte $\mathrm{B}$.

Dessa forma, quando utilizadas sem adoção de princípios conservacionistas, terras com esse tipo de declive podem apresentar sulcos e voçorocas, requerendo práticas intensivas de controle à erosão, desde o início de sua utilização agrícola.

A respeito do declive forte ondulado, essas terras apresentam grande suscetibilidade à erosão, visto que ocorrem em relevo forte ondulado, os quais podem ser maiores ou menores, dependendo das condições físicas do local. Porém, na maioria dos casos, a prevenção à erosão é difícil e dispendiosa, podendo ser antieconômica (Capoane, 2019).

Silva (2004) concluiu, em estudo na bacia hidrográfica do rio Paracatu, que as áreas mais críticas de perda do solo na bacia estão associadas a altas declividades, fato que implica diretamente na necessidade de estudos de planejamento ambiental no município. Ressalta-se que as condições planas do 
Revista Brasileira de Geografia Física v.014, n.04 (2021) 2352

relevo permitem o uso de mecanização agrícola, modificando-se rapidamente a paisagem através da

retirada expressiva da cobertura vegetal natural (Tonini et al., 2019).

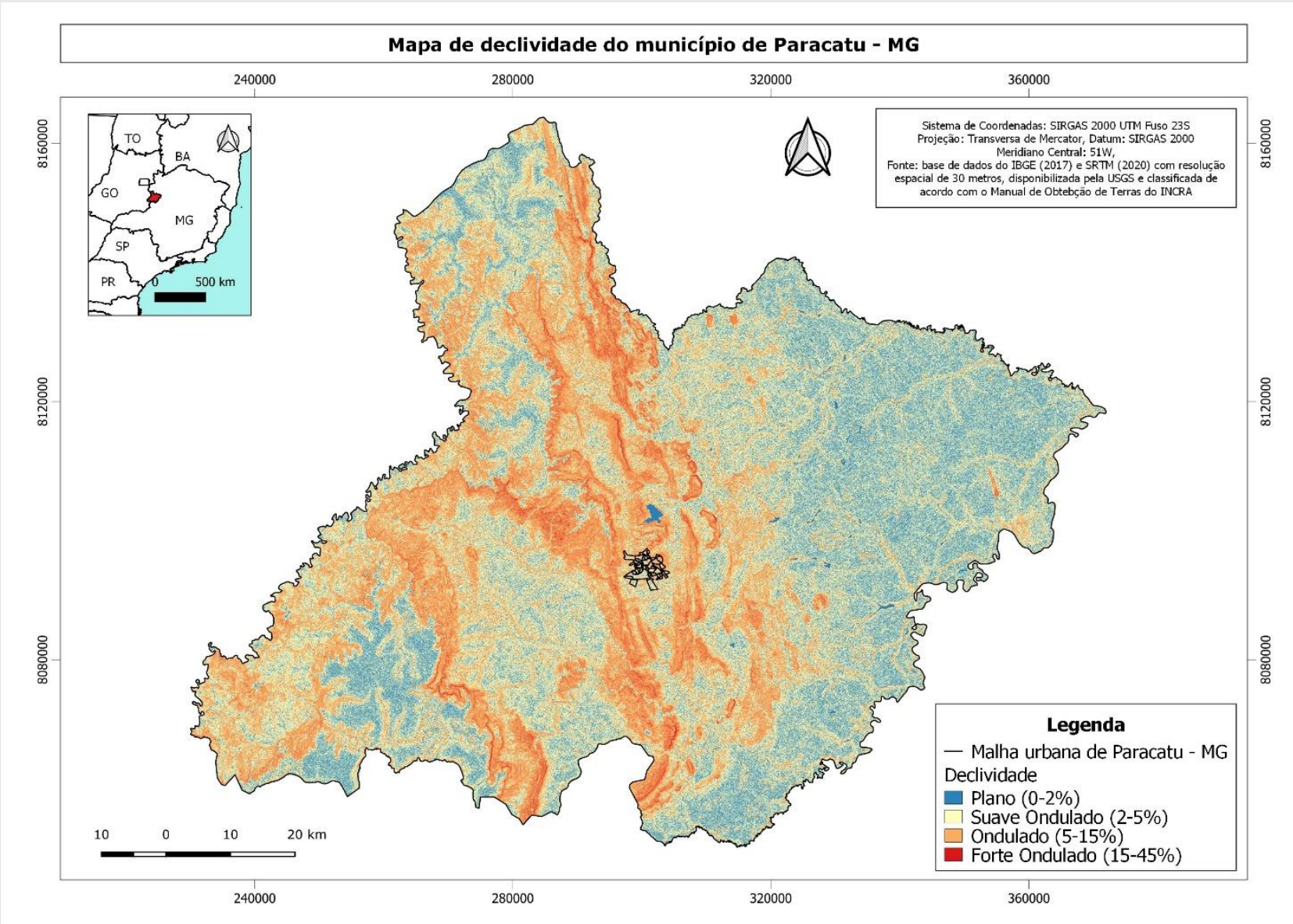

Figura 2. Classes de declividade do município de Paracatu - MG.

Convém destacar que as áreas com declividade entre $13-20 \%$ são indicadas para a exploração de culturas permanentes, visto que esse tipo de plantio proporciona ao solo uma maior proteção. Em relação as áreas com relevo forte ondulado (20-45\%), essas devem ser destinadas para o desenvolvimento de atividades como pecuária e silvicultura, além de existir a possibilidade de serem utilizadas para conservação ambiental, visto que evitar-se-á problemas de erosão (Cobra et al., 2019; Gouveia e Ross, 2019).

O mapa hipsométrico (Figura 3) permitiu identificar variações de altitude na área de estudo. A comparação visual entre o mapa hipsométrico e o de declividade demonstra que as regiões com proeminência de baixa elevação apresentam um índice de declive plano.

Com relação aos valores de maior altitude, esses estão localizados em um divisor de água do município, local que separa a bacia do rio Paranaíba e a bacia do rio São Francisco, conforme a Figura 4.
O mapa de uso e cobertura da terra é apresentado na Figura 5. O resultado da classificação supervisionada condiz com o cenário existente no município, em que o PIB está concentrado nas atividades de agricultura e mineração (IBGE, 2021).

Vale destacar, e é notório, a escassez de recursos hídricos na região. $\mathrm{O}$ contexto é confirmado com a crise hídrica ocorrida no município no ano de 2017. A Tabela 4 apresenta o cálculo das áreas classificadas no uso e cobertura da terra do município. Ressalta-se que, para a data analisada, houve uma grande porcentagem de solo exposto no município. Esse fato pode estar relacionado pela

época de colheita de grãos (feijão e milho), fato que corrobora com a concentração da agricultura no município.

Os resultados apresentados corroboram ao estudo de Almeida et al. (2017) em uma bacia hidrográfica do município de Paracatu. Os autores verificaram que a principal cobertura do solo da região correspondia à agricultura, principalmente devido às formas de relevo e solo que possibilitam a 
Revista Brasileira de Geografia Física v.014, n.04 (2021) 2352

mecanização agrícola. Ademais, ainda por meio dos resultados dos autores, nas áreas correspondentes às por meio de pivôs centrais e com pastagem pouco incidente.

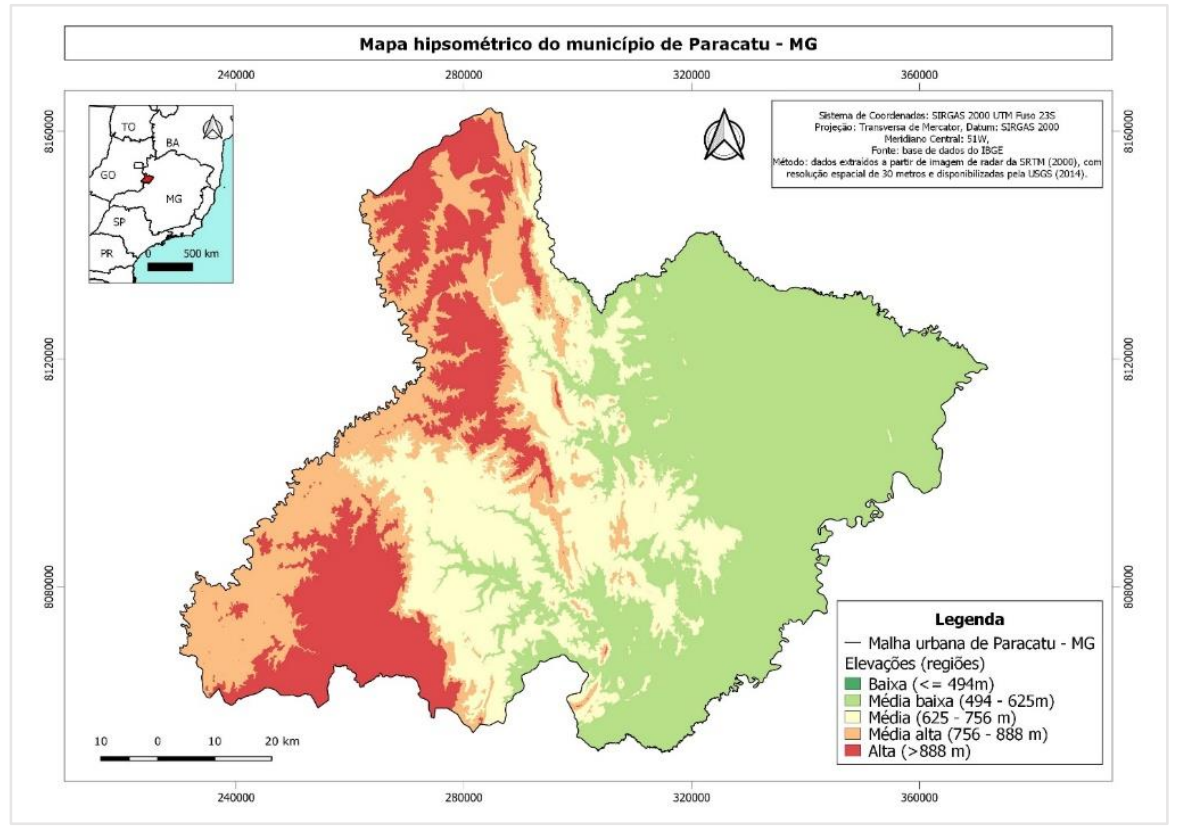

Figura 3. Mapa hipsométrico do município de Paracatu - MG.

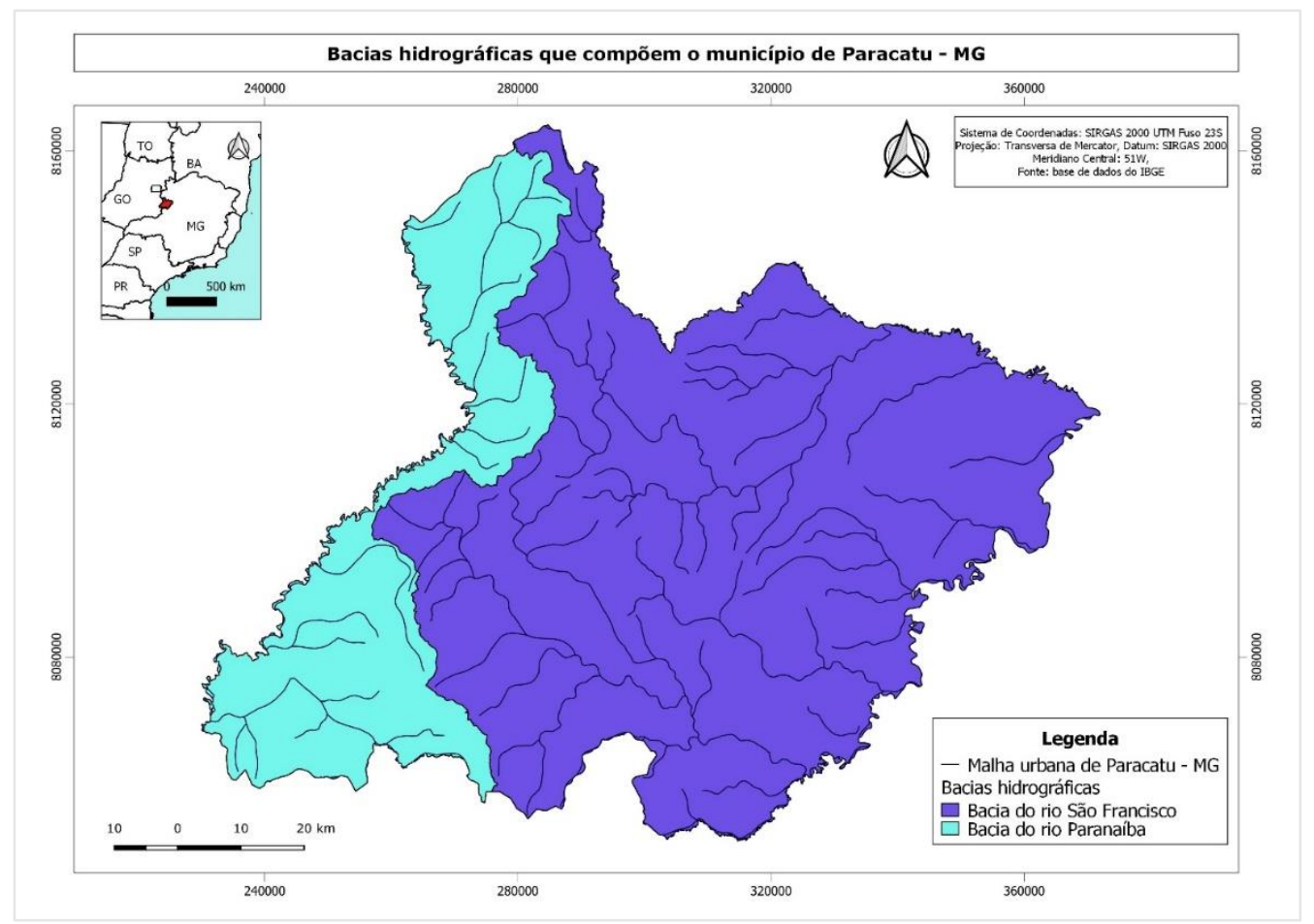

Figura 4. Mapa hidrográfico do município de Paracatu - MG. 
Revista Brasileira de Geografia Física v.014, n.04 (2021) 2352

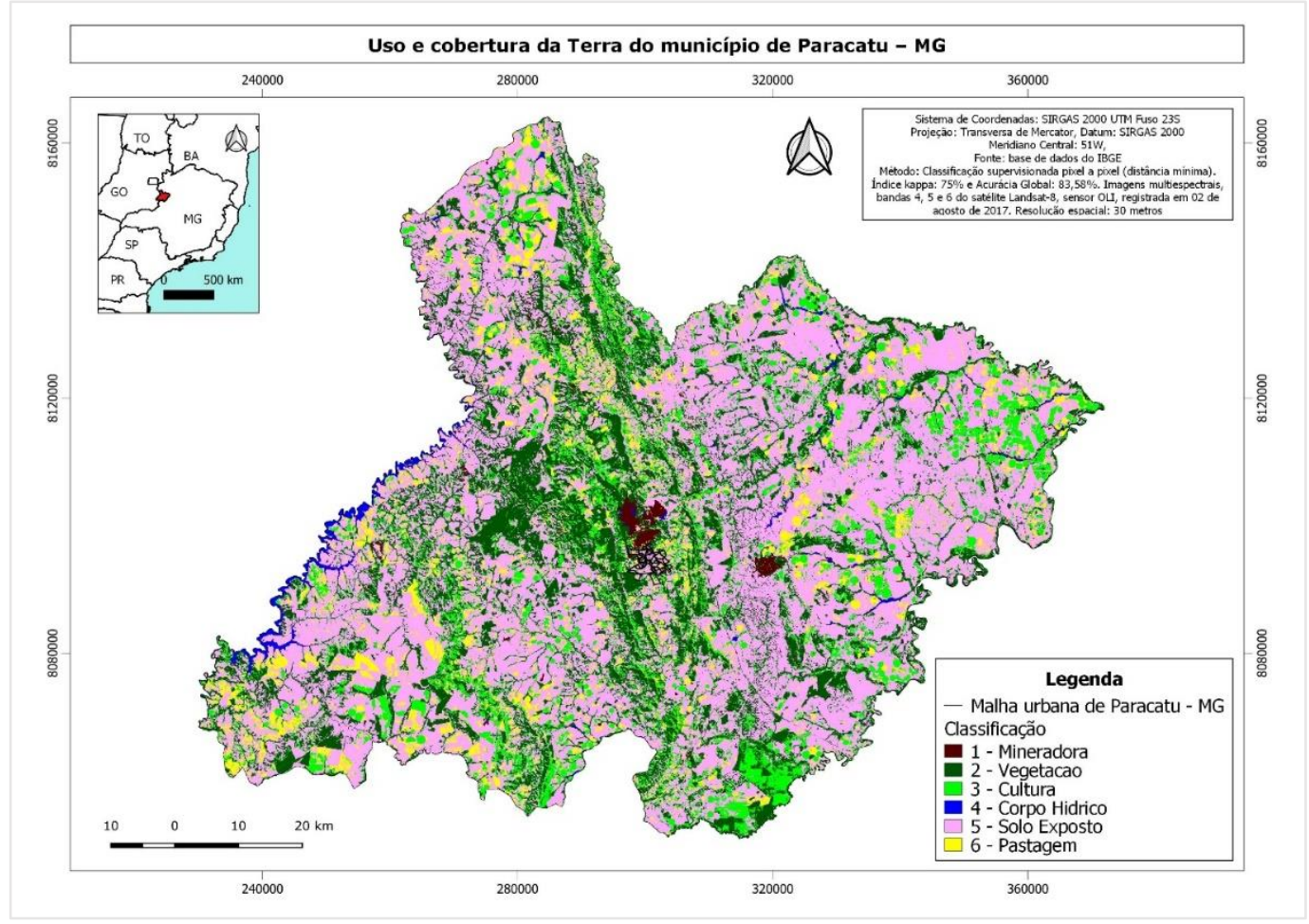

Figura 5. Uso e cobertura da Terra do município de Paracatu - MG.

Tabela 4. Cálculo das áreas ocupadas no município de Paracatu - MG.

\begin{tabular}{c|c|c}
\hline $\begin{array}{c}\text { Classes de Uso } \\
\text { e Cobertura }\end{array}$ & $\begin{array}{c}\text { Área } \\
\left(\mathrm{km}^{2}\right)\end{array}$ & Área $(\%)$ \\
\hline Mineradora & 97,10 & 1,18 \\
\hline Vegetação & $1.865,77$ & 22,60 \\
\hline Cultura & $1.202,05$ & 14,55 \\
\hline Corpo hídrico & 68,83 & 0,83 \\
\hline Solo exposto & $4.294,50$ & 52,00 \\
\hline Pastagem & 586,40 & 7,10 \\
\hline Área urbana & 142,80 & 1,74 \\
\hline Total & $8.257,45$ & 100,00 \\
\hline
\end{tabular}

Em Paracatu, os solos são dos tipos: Cambissolo; Gleissolo; Latossolo; Neossolo e; Argissolo. Na
Figura 6 é apresentado o mapa pedológico dessa área. Ressalta-se a presença, em sua maioria, do tipo de solo Latossolo, que, de acordo com o Sistema Brasileiro de Classificação dos Solos (SiBCS) (2013), trata-se de um solo em estágio avançado de intemperização, muito evoluído e destituído de minerais primários. São, em geral, solos fortemente ácidos, com baixa saturação por bases e distróficos. Ocorrem, entretanto, solos com saturação por bases média e até mesmo alta, encontrados geralmente em zonas que apresentam estação seca pronunciada, semiáridas ou não, ou ainda por influência de rochas básicas ou calcárias. 
Revista Brasileira de Geografia Física v.014, n.04 (2021) 2352-2368.

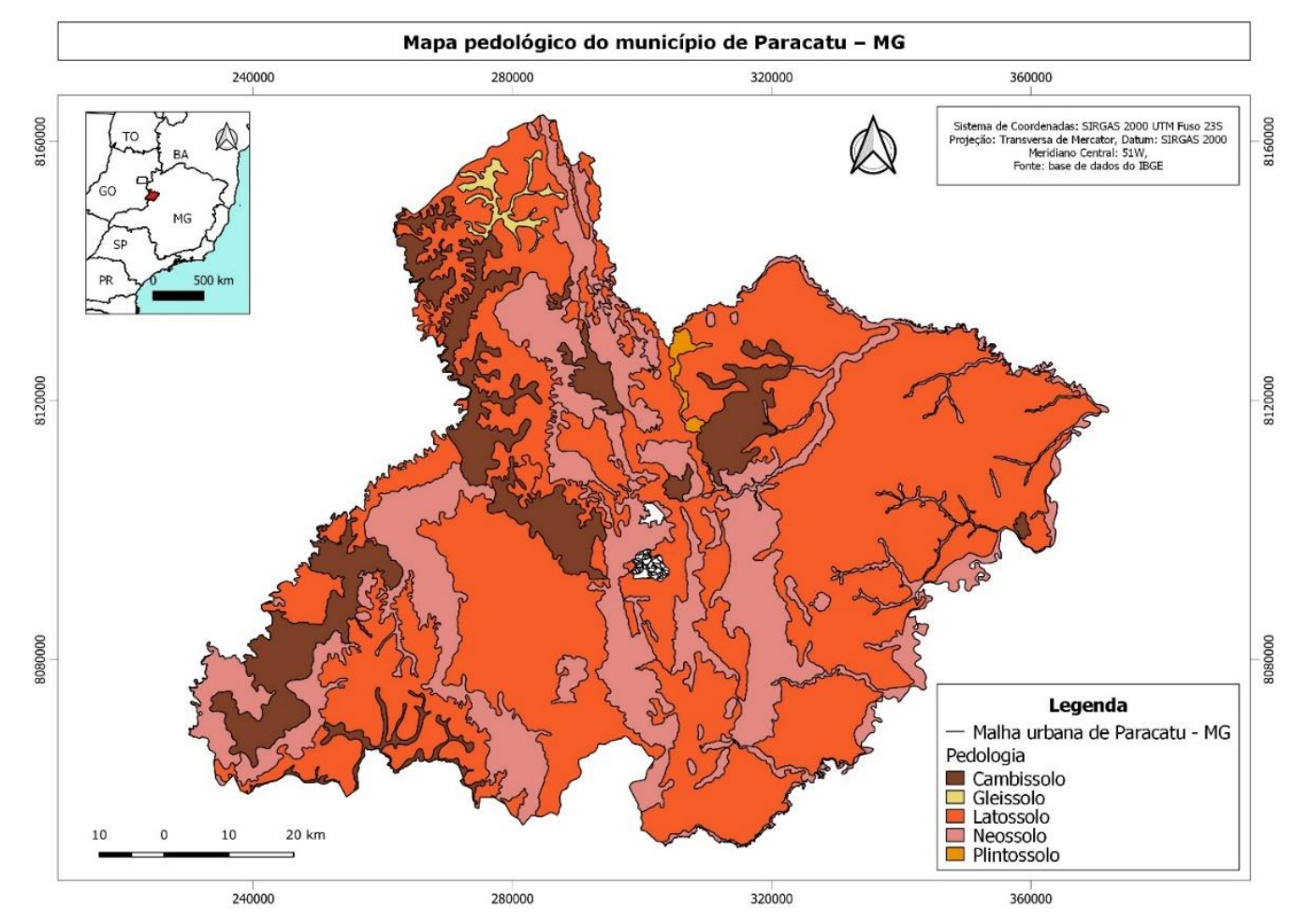

Figura 6. Mapa pedológico do município de Paracatu - MG.

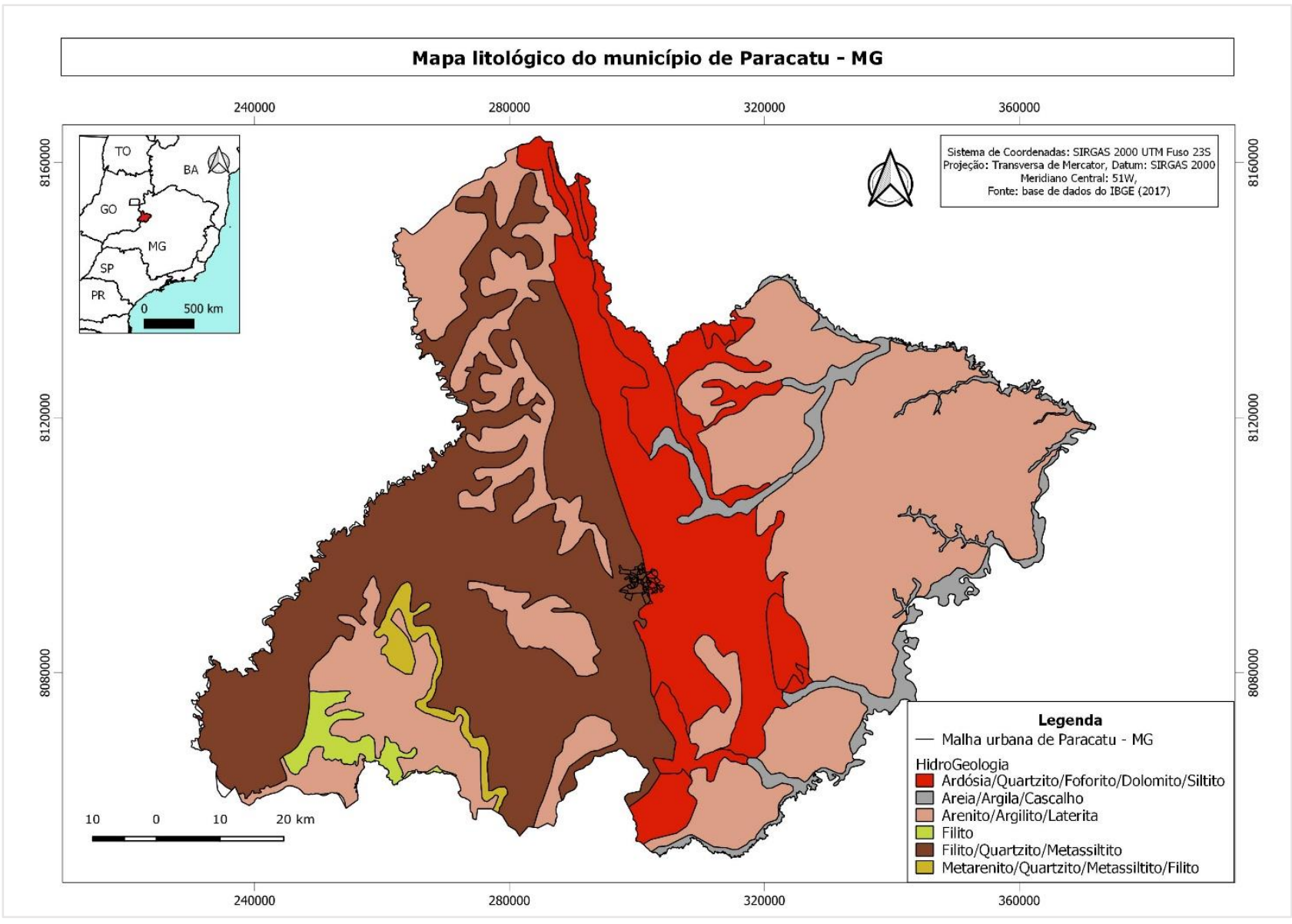

Figura 7. Mapa litológico do município de Paracatu - MG. 
Revista Brasileira de Geografia Física v.014, n.04 (2021) 2352-2368.

Os Neossolos, também encontrados no município (Figura 6), ocorrem em áreas dissecadas com relevo forte ondulado a montanhoso. Um estudo (Montagnon et al., 2008) realizado no município, em diferentes pontos com a presença de

Latossolo, mostrou as concentrações totais de Cadmo (Cd), $\mathrm{Pb}$ e $\mathrm{Zn}$ nos solos, as quais são muito superiores aos teores médios dos solos comuns, ou mesmo dos Latossolos da zona intertropical.

Em relação ao aspecto geológico (Figura 7), o município possui afloramentos de origem sedimentar e metamórfica. Dentre as litologias predominantes na área, destaca-se, a sequência argilosa, onde ocorrem mineralizações de $\mathrm{Zn}$ e $\mathrm{Pb}$ pela multinacional NEXA, seguido de sequências com filitos, com intercalações de quartzitos onde são hospedadas mineralizações de Au pela multinacional KINROSS. A litologia da região é caracterizada por suas variações químicas que podem estar relacionados com as atividades de mineralização. As rochas com filitos possuem valores elevados de Dioóxido de Silício ((SiO2), Zircônio (Zr), Vanádio $(\mathrm{V})$, Cromo $(\mathrm{Cr})$ e Alumínio (Al) em relação as rochas mineralizadas. Em relação ao quartzo, as rochas apresentam alto grau de deformação e são enriquecidos em ( $\mathrm{Au}$ ), Prata (Ag), Arsênio (As), $\mathrm{Pb}$, Zn, Carbono (C) e Enxofre (S). Estudos das rochas mineralizadas e não mineralizadas realizados no Morro de Ouro indicaram que a mineralização está presente em uma área marcada por diferenças geológicas, deformacionais e geoquímicas (Almeida, 2009; Sotero et al., 2019).

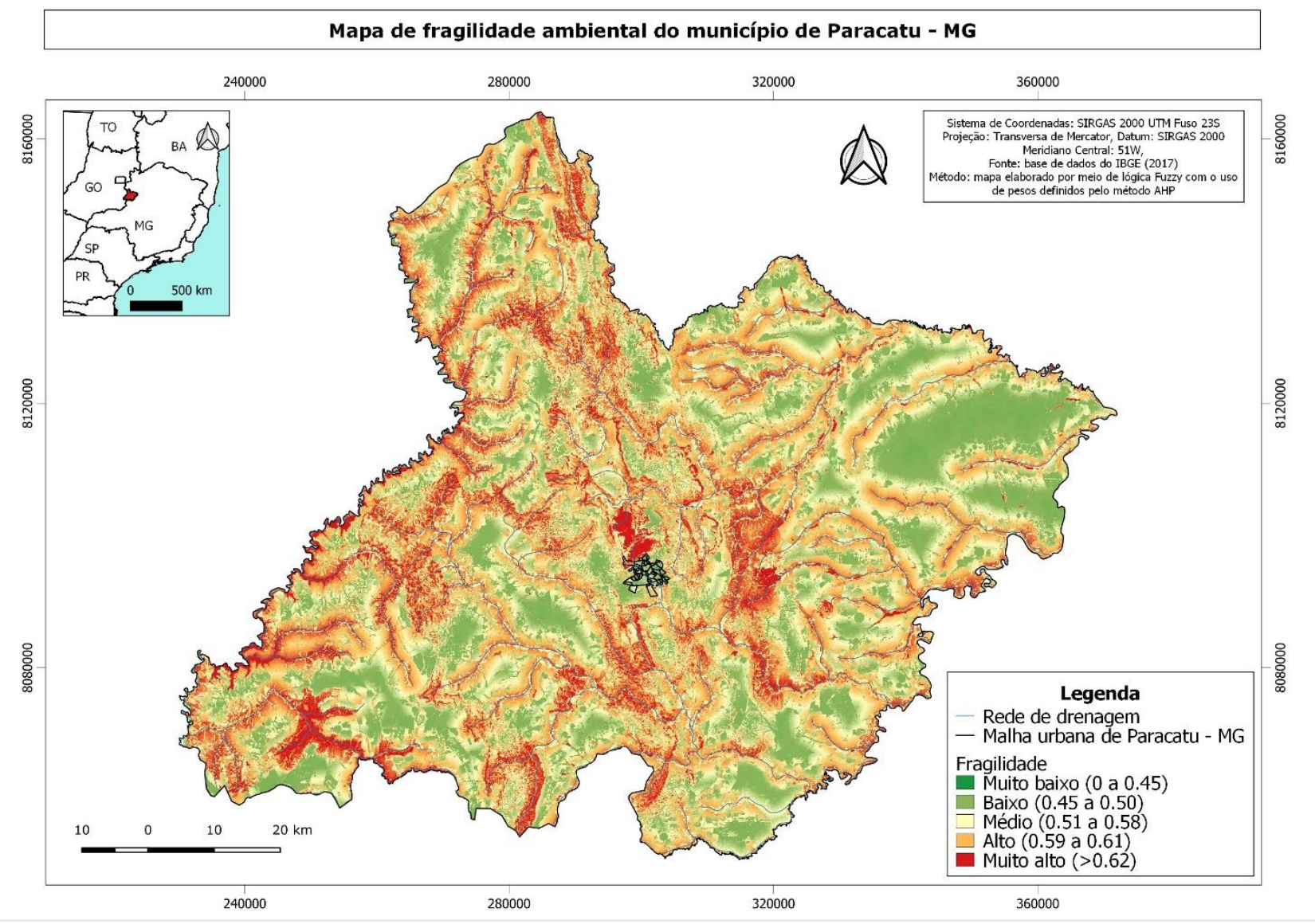

Figura 8. Mapa de fragilidade ambiental do município de Paracatu - MG.

Com relação ao mapa de fragilidade ambiental (Figura 8), verificou-se que as áreas nas proximidades dos corpos hídricos estão, predominantemente, com a fragilidade ambiental alta e/ou muito alta. Tal situação pode ser estar relacionada, dentre outros fatores, com a presença do solo exposto no município e/ou com a falta das matas ciliares. Convém destacar que as áreas ao entorno dos corpos hídricos são consideradas Áreas de Preservação Permanente (APP) pelo Código Florestal Brasileiro (Lei 12.651/2012), devendo ser, portanto, protegidas por vegetação arbórea.

Ao se comparar a área de declive municipal com a área de fragilidade ambiental, verifica-se que a área no município considerada de declive plano foi a área que demonstrou os menores valores de fragilidade ambiental (muito baixo ou baixa). Essas 
Revista Brasileira de Geografia Física v.014, n.04 (2021) 2352

áreas não apresentam riscos de intensivos processos erosivos intensos, sendo apropriada para a destinação de atividades agropecuárias. Ademais, a área de transição entre o declive plano e o declive ondulado para forte ondulado demonstrou-se com fragilidade ambiental muito alta. Essa região de transição é, também, a área de transição hipsométrica entre elevação baixa e média alta.

Com relação a área da mineradora e a malha urbana municipal, essa é, em sua totalidade, de fragilidade alta e muito alta. Essa situação reflete a falta de planejamento urbano ambiental do município.

Em suma, os dados apresentados podem ser utilizados como suporte ao ZA municipal, principalmente com o intuito de subsidiar áreas a serem escolhidas para a implantação de novas atividades antrópicas. Ademais, o município de Paracatu encontra-se, atualmente, em processo de elaboração e aprovação do novo plano diretor municipal. Nesse sentido, a utilização do mapa de fragilidade ambiental do município poderá auxiliar, principalmente, nas tomadas de decisões dos gestores públicos.

\section{Considerações Finais}

Com base nos resultados dos mapas temáticos, verificou-se que o município de Paracatu apresenta características de susceptibilidade a impactos ambientais negativos, possivelmente oriundas da atividade agropecuária e de extração de minérios. Com relação à atividade de mineração, essa encontra-se nas proximidades da malha urbana do município, tornando a área extremamente frágil no quesito ambiental. Ademais, esse resultado pode ser interpretado como uma deficiência de planejamento físico-territorial na área em estudo.

Em relação à atividade agropecuária na região, conclui-se que a topografia do município exige um manejo adequado do solo, visto que, caso feito de forma equivocada, pode ocasionar, diretamente, em erosões, voçorocas e assoreamento dos corpos hídricos.

Por fim, perante a atual crise de infraestrutura urbana que acomete os municípios do país devido à falta de planejamento urbano e ambiental, os resultados do presente trabalho auxiliam a direcionar a ocupação do solo urbano e das atividades antrópicas na região em estudo. Portanto, esses resultados podem contribuir com o trabalho dos órgãos fiscalizadores relacionados ao meio ambiente em Paracatu. Nesse sentido, os produtos cartográficos gerados nesse estudo poderão ser utilizados como forma de subsídio ao planejamento físico-territorial desse município, visando o uso racional dos recursos naturais.

\section{Agradecimentos}

Os autores dessa pesquisa agradecem a Prefeitura de Paracatu - MG pelo apoio e pelo suporte bibliográfico para a realização desse trabalho.

\section{Referências}

Almeida, B. S. 2009. Geoquímica dos filitos carbonosos do depósito Morro do Ouro, Paracatu, Minas Gerais. Dissertação (Mestrado em Geologia). Brasília, Universidade de Brasília.

Almeida, F. P., Romão, P. A., Nascimento, D. F. T., 2017. Vulnerabilidade à perda de solo na bacia do Córrego das Crioulas em Paracatu-MG. Os Desafios da Geografia Física na Fronteira do Conhecimento.

DOI: https://doi.org/10.20396/sbgfa.v1i2017.1798

Acesso em: 19 jun. 2020.

Araújo, E. R., Oliviera, R. D., Fernandes, F. R. C., 2014. Atividade mineradora gera riqueza $\mathrm{e}$ impactos negativos nas comunidades e no meio ambiente. CETEM/MCTI, Rio de Janeiro.

Atlas do desenvolvimento humano no Brasil. Perfil Paracatu, MG. 2021. Disponível em: http://www.atlasbrasil.org.br/acervo/biblioteca. Acesso em: 11 fev. 2021.

Baldwin, J. H. 2019. Environmental planning and management. Westview Press.

BRASIL. 2012. Lei $\mathrm{N}^{\circ} 12.651$, de 25 de maio.

BRASIL. Ministério Público Federal. Procuradoria da República em Minas Gerais. Justiça impede mineradora de construir estrada em terras de comunidade quilombola. Patos de Minas, 10 maio 2010. Disponível em:

http://www.mpf.mp.br/mg/sala-deimprensa/noticiasmg/justica-impede-mineradora-de-construir-estradaem-terras-de-comunidade-quilombola-em-minasgerais. Acesso em: 15 dez. 2020.

Caggy, A. L., Almeida, E. S. 2020. Aplicação de metodologia híbrida AHP \& lógica fuzzy para tomada de decisão na gestão de projetos em uma indústria florestal. Gestão \& Produção. DOI: https://doi.org/10.1590/0104-530x4225-20. Disponível em: 07 fev. 2021.

Câmara, G., Monteiro, A. M. V., 2004. Conceitos básicos em ciência da geoinformação. Introdução 
Revista Brasileira de Geografia Física v.014, n.04 (2021) 2352

à ciência da geoinformação. Disponível em: http://www.selperbrasil.org.br/cursos/leituras/Ge o_conceitos.pdf Acesso em: 18 jan. 2021.

Capoane, V. 2019. Susceptibilidade a erosão na bacia hidrográfica do córrego Guariroba, Campo Grande, Mato Grosso do Sul. DOI: https://doi.org/10.22571/2526-4338180. Acesso em: 14 fev. 2021.

Carvalho, A. P. C., Guerrero, J. V. R., Silva, E. V. E., Pinto, M. J. R., Vaz, R. M. G. F. C. V., Pereira, C. T., Lorandi, R., Lollo, J. A., Moschini, L. E., 2020. Fragilidade Ambiental à Erosão em uma Bacia Hidrográfica Antropizada no Nordeste do Estado de São Paulo, Brasil. Anuário do Instituto de Geociências.

DOI:

http://dx.doi.org/10.11137/2019_3_07_18.

Acesso em: 05 jan. 2021.

Castilhos, Z. C., Capitani, E. M., Jesus, I. M., Bidone, E. D., Mello, W. Z., Lima, M. O., Faial, K. R. F., Mataveli, L. R. V., Arauz, L. J., Silva, L. I. D., Ferreira, A. P., Távora, R. S., Mertens, F., 2020. Avaliação da contaminação ambiental por arsênio e estudo epidemiológico da exposição humana em Paracatu-MG - Brasil. Fronteiras: Journal of Social, Technological and Environmental Science. DOI: http://dx.doi.org/10.21664/22388869.2020v9i1.p186-12. Acesso em: $03 \mathrm{dez}$. 2020.

Cobra, R. L. Silva, R. C. Oliveira, G. F. A. D., Miranda, D. L., Leonardo, F. A., Silva, M. L. 2019. Geoprocessamento aplicado ao levantamento e avaliação de solos: proposta de avaliação de terras para fins agrícolas no Município de Inconfidentes-MG. Revista Brasileira de Geografia Física. DOI: https://doi.org/10.26848/rbgf.v12.2.p397-411. Acesso em: 18 fev. 2021.

Collins, B., Kumral, M. 2020. Environmental sustainability, decision-making, and management for mineral development in the Canadian Arctic. International Journal of Sustainable Development \& World Ecology. DOI:

https://doi.org/10.1080/13504509.2019.1684397.

Acesso em: 25 jan. 2021.

EMBRAPA. Empresa Brasileira de Pesquisa Agropecuária. 1997. Solos. Manual de métodos de análise de solo.

EMBRAPA. Empresa Brasileira de Pesquisa Agropecuária. 2014. Geotecnologias e geoinformação: o produtor pergunta, a Embrapa responde.

EMBRAPA. Empresa Brasileira de Pesquisa Agropecuária. 2013. Sistema brasileiro de classificação de solos.

EPAMIG. Empresa de Pesquisa Agropecuária de Minas Gerais. 2014. Solos e avaliação do potencial agrossilvipastoril das microrregiões Paracatu e Unaí - Minas Gerais.

García, E. G. S. 2019. Implementación de software libre para la digitalización de información geológica e identificación de zonas de deslizamientos, caso de estudio hoja Huehuetenango núm. 1961 IV-G escala 1: 50,000. Tese de Doutorado. Universidad de San Carlos de Guatemala. Guatemala

Gonçalves, S. R. A., Araújo, R. R., Imai, N. N., 2016. Mapeamento do grau de fragilidade com processo analítico hierárquico e operadores fuzzy gama na detecção áreas de fragilidade ambiental. Revista Brasileira de Cartografia.

Gouveia, I. C. M. C., Ross, J. L. C. 2019. Fragilidade ambiental: uma proposta de aplicação de Geomorphons para a variável relevo. Revista do Departamento de Geografia. DOI: https://doi.org/10.11606/rdg.v37i0.151030.

Acesso em: 08 jan. 2021.

Hannan, M. A., Zamre, A. G., Murshadul, H., Pin, J. K., Aini, H., Azah, M. 2019. Fuzzy logic inverter controller in photovoltaic applications: Issues and recommendations. DOI:

10.1109/ACCESS.2019.2899610. Acesso em: 18 jan. 2021.

IBGE. Instituto Brasileiro de Geografia e Estatística. 2021. Banco de dados geográficos.

IBGE. Instituto Brasileiro de Geografia e Estatística. Censo Demográfico 2010.

IBGE. Instituto Brasileiro de Geografia e Estatística. 1999, 2007, 2009. Manuais Técnicos em Geociências.

IBGE. Instituto Brasileiro de Geografia e Estatística. 2021. Produto Interno Bruto dos Municípios.

IGAM. Instituto Mineiro De Gestão Das Águas. 2020. Monitoramento da qualidade das águas do Estado de Minas Gerais.

INCRA. Instituto Nacional de Colonização e Reforma Agrária. 2006. Manual de obtenção de terras e perícia judicial.

KINROSS. Kinrros Gold Corporation. 2021. Conheça a Kinross.

Krishnan, R. S., Julie, E. G., Robinson, Y. H., Raja, S., Kumar, R., Thong, P. H., Son, L. H. 2020. Fuzzy logic based smart irrigation system using internet of things. Journal of Cleaner Production. DOI:

https://doi.org/10.1016/j.jclepro.2019.119902.

Acesso em: 23 jan. 2021.

EMBRAPA. Empresa Brasileira de Pesquisa Agropecuária. 1997. Solos. Manual de métodos de análise de solo.

Machado, V. B., Medeiros, I., Ruiz, R. F., 2018. Aplicabilidade da lógica fuzzy na gestão de risco 
Revista Brasileira de Geografia Física v.014, n.04 (2021) 2352

de desastres geotécnicos do estado de Santa Catarina. Revista Gestão \& Sustentabilidade Ambiental.

DOI: http://dx.doi.org/10.19177/rgsa.v7e0201866-85

Acesso em: 15 fev. 2021.

Messias, C. G., FERREIRA, M. C. 2017. Aplicação do método de classificação contínua fuzzy para o mapeamento da fragilidade do terreno em relação à ocorrência de ravinas no Parque Nacional da Serra da Canastra. Raega-O Espaço Geográfico em Análise. DOI:

http://dx.doi.org/10.5380/raega.v39i0.42914. Acesso em: 13 jan. 2021.

Montagnon, F., Becquer, T., Martins, E. S., Reatto, A., Fuks, S. D. 2008. Distribuição dos teores de $\mathrm{Cd}, \mathrm{Pb}$ e $\mathrm{Zn}$ em solos da região de ParacatuVazante, MG. Geo Logiques.

Naime, U. B., Motta, P. E. F., SILVA, D. C., Simão, M. L. R., Santos, A. J. R. 2014. Solos e avaliação do potencial agrossilvipastoril das microrregiões Paracatu e Unaí-Minas Gerais. Embrapa SolosLivro científico (ALICE).

NEXA. 2021. Conheço a Nexa: história.

Oliveira, L. N., Cunha, L. J. S., Cruz, M. L. B., Pereira, E. C. 2020. Índice de resiliência natural em bacias hidrográficas: o caso do baixo curso do Rio Poti. Caminhos de Geografia. DOI: https://doi.org/10.14393/RCG217551190. Acesso em 12 jan. 2021.

Peixoto, R. A. O., Fernandes, J. C., Schmidt, M. A. R., Pereira, C. E. 2019. Análise multicritério com uso da AHP para avaliação temporal na vulnerabilidade ambiental: estudo de caso na bacia hidrográfica do uberabinha, MG. Revista Gestão \& Sustentabilidade Ambiental. DOI: http://dx.doi.org/10.19177/rgsa.v8e32019141158. Acesso em 03 fev. 2021.

Pereira, P. R. M., Costa, F. W. D., Júnior, A. R. G. 2019. Geoprocessamento aplicado na análise da fragilidade ambiental do município de Brejo, Maranhão. Revista equador.
Rezende, P. S., Marques, D. V. 2017. Mapeamento de riscos a inundação na área urbana de ParacatuMG. Os Desafios da Geografia Física na Fronteira do Conhecimento. DOI:

https://doi.org/10.20396/sbgfa.vli2017.2198. Acesso em: 14 jan. 2021.

Santos, C. R., Rocha, P. C. 2019. Análise integrada de dados espaciais utilizando multicritério para a delimitação de corredores ecológicos. Brazilian Geographical Journal: Geosciences and Humanities research medium. Saaty, T. L. 1990. How to make a decision: the analytic hierarchy process. European journal of operational research. DOI:

https://doi.org/10.1016/0377-2217(90)90057-I.

Acesso em: 22 jan. 2021.

Silva, M. M. S., Santos, J. E. A., Silva, G. R. D., Lunardi, V. O., Lunardi, D. G. 2021. Percepção de atores sociais como subsídio ao zoneamento ambiental de uma unidade de conservação costeira no nordeste do brasil. Raega-O Espaço Geográfico em Análise. DOI:

http://dx.doi.org/10.5380/raega.v50i0.67678.

Acesso em: 17 fev. 2021.

Silva, V. C. 2004. Estimativa da erosão atual da bacia do Rio Paracatu (MG/GO/DF). Pesquisa Agropecuária Tropical.

Sotero, M. P., Caxito, F. A., Dias, P. H. A., Sotero, B. A. 2019. Análise de fácies e ambientes deposicionais do Grupo Vazante na região da mina de Morro Agudo, Paracatu, noroeste do estado de Minas Gerais. Geologia USP. DOI: https://doi.org/10.11606/issn.23169095.v19144761. Acesso em: 13 fev. 2021.

Tonini, H., Falavinha, A. F., Magalhães, S. 2019. Dimensionamento de um sistema de integração lavoura-pecuária-floresta. Embrapa Pecuária SulComunicado Técnico (INFOTECA-E). 